\title{
PERSONAL FACTORS AS A CAUSE OF DIFFERENCES IN PRESCRIBING BY GENERAL PRACTITIONERS
}

\author{
BY \\ C. R. B. JOYCE, M.A., B.Sc., PH. D. \\ Reader in Psychopharmacology, Department of Pharmacology, \\ J. M. LAST*, M.B., D.P.H., \\ Senior Lecturer in Social Medicine, Department of Social Medicine, \\ London Hospital Medical College, London E.I \\ AND \\ M. WEATHERALL, D.M., D.SC., \\ Director of Therapeutic Research, Wellcome Research Laboratories, Beckenham, Kent
}

The quantity and identity of drugs prescribed under the National Health Service vary widely between different towns (Martin, 1957; Benjamin and Ash, 1964). The reasons are not well understood, but differences of morbidity and mortality in the towns are not solely responsible (Lee, 1964). The differences in prescribing between towns remain relatively stable over months and years, so that the rank order of towns with different rates or different costs of prescribing is fairly stable (Ministry of Health Reports, 1963). In any town, there is considerable variation between individual doctors, and there is some evidence that the behaviour of particular doctors is also fairly stable over periods of time. Doctors differ not only in how much and how often they prescribe but also in what they prescribe (Weatherall, 1964), and it is desirable to understand the origin of such differences. A study of all the prescriptions issued in one month in each of three industrial towns has already been reported (Lee, 1964; Lee, Draper, and Weatherall, 1965). Most of the practitioners concerned in that study who had over 1,000 patients on their N.H.S. lists were interviewed about various aspects of their practice. The present paper describes these interviews and their analysis in relation to the prescribing of the doctors interviewed.

\section{The INVestigation}

\section{Methods}

During the inquiry into prescribing, one of the authors (J.M.L., a former general practitioner with 6 years' experience in Australia) conducted semistructured interviews (see Table I) with 93 of the

*Now in the Department of Social Medicine, University of Edinburgh.
320 general practitioners involved. These 93 consisted of all but two of those in the smallest town, and 50 per cent. of those in the larger two, who had a list of over 1,000 patients in the Executive Council area. These doctors ( 27 per cent. of the total) issued 39 per cent. of all the prescriptions studied. One doctor refused to be interviewed and a second was unavailable for reasons of health. Differences between the patterns of response to the interview in the three towns are discussed in Part I of thi $\vec{S}^{+}$ paper. The items had been chosen after discussion with colleagues and general practitioners and a pilot trial on a small group of practitioners from an area not involved in the main study.

\section{ANalysis of Results}

Many but not all items could readily be given a score. Some, such as the response to the question "How many partners have you?" or "Are you on the Midwifery Register?", were matters of relatively hard fact, although it may be noted that the answers given did not always agree with those obtained from published sources. Other items asked the practitioners to estimate theoretically measurable data, such as the total number of patients they had seen during the previous week, and the number suffering from depression, coronary heart disease, and other conditions in the previous month. Still other items asked about attitudes and matters that could not be measured objectively: e.g. "What proportion of patients make unreasonable demands upon you?"; "Do you feel that you are an integral co part of the N.H.S.?" There are of course no hard $\stackrel{D}{\Phi}$ and fast borderlines between the various classes of $\stackrel{D}{+}$ information sought. Those items that could be $T$ scored on a quantal basis or on a ratio or interval 
TABLE I

\begin{tabular}{|c|c|c|c|}
\hline $\begin{array}{l}\text { Question } \\
\text { (not in order used at interview) }\end{array}$ & $\begin{array}{l}\text { Town } 1 \\
24 \text { Doctors }\end{array}$ & $\begin{array}{c}\text { Percentage replying "Yes" } \\
\text { Town } 2 \\
44 \text { Doctors }\end{array}$ & $\begin{array}{c}\text { Town } 3 \\
25 \text { Doctors }\end{array}$ \\
\hline 1. Are your practices separate as far as patients are concerned? & 79 & 45 & 52 \\
\hline 2. Do you practise from home? & 50 & 45 & 4 \\
\hline 3. Have you any branch surgeries? & 79 & 59 & 64 \\
\hline 4. Have you an assistant? & 25 & 20 & 4 \\
\hline 5. Are you in a rota system for nights and/or weekends off? & 100 & 84 & 84 \\
\hline 6. *Do you think you have adequate time free from the worries of practice? & 50 & 59 & 52 \\
\hline 7. Do you use an appointment system? & 33 & 34 & 40 \\
\hline 8. Do you have any private patients? & 13 & 55 & 28 \\
\hline 9. *Do you do any other medical work outside your general practice? & 63 & 53 & 68 \\
\hline $\begin{array}{l}\text { 10. Some modern drugs have unpleasant side effects: have you had any } \\
\text { problems with any of these? (Average of positive answers to five } \\
\text { named drugs) }\end{array}$ & 38 & 38 & 42 \\
\hline $\begin{array}{l}\text { 11. *Do you think you had adequate training in therapeutics as a medical } \\
\text { student? }\end{array}$ & 38 & 45 & 60 \\
\hline 12. Do you take the Lancet? & 4 & 16 & 20 \\
\hline $\begin{array}{l}\text { 13. *Would you say that you (and your partners) work in isolation from } \\
\text { the rest of the health services? }\end{array}$ & 38 & 50 & 42 \\
\hline 14. *Do you think this is a good area to be a general practitioner? & 75 & 81 & 88 \\
\hline 15. *Is there much competition for patients? & 33 & 2 & 30 \\
\hline $\begin{array}{l}\text { 16. *Should you or a member of your family be ill, do you ask another } \\
\text { G.P. to be your medical attendant? }\end{array}$ & 50 & 52 & 64 \\
\hline
\end{tabular}

* The indeterminate replies of a small number of doctors to these questions were ssored as halves.

scale were analysed appropriately, but much of the material could not be treated in this way. Sixteen scales were therefore agreed by four assessors (see Appendix) as relevant to judgements about the contents of the interviews. These assessors (two medical, including J.M.L., and two non-medical graduates, one of them C.R.B.J.) read the 93 interview protocols and assigned each practitioner a number between 0 and 5 (including semi-intervals) on each scale. Preliminary testing showed that a significant difference in the four sets of scores was due to the use by the non-medical judges of consistently lower values. Since these differences were randomly distributed over the three towns and the 93 doctors, they did not systematically affect the mean scores, and further calculations - a principal component analysis (Harmer, 1961)-used the sum of the four judges' scores as the individual value. This analysis was made with the standard library programme LS9 on the London Hospital National Elliott 803 Computer, and the results are presented in Part II.

Finally, the individual loadings on the components of this analysis were correlated with components of a similar analysis upon the prescribing patterns of the same doctors. These findings make up Part III.

\section{FINDINGS}

\section{PART I. Differences betweEn TOWNS}

Some differences between the three towns, the identities of which are concealed in the same way and for the same reasons as in the preceding reports of this work (see Lee, 1964), can be deduced from Table I.

In Town 1 the number of partnerships was smallest and the median number of partners lowest, and almost twice as many of the partnerships that did exist operated separate lists: doctors there practised more frequently from their homes, had proportionately more branch surgeries, and (as would be expected) more often employed an assistant in the practice than did those in the other towns. Only one doctor in Town 3 practised from home and only one had an assistant. All doctors in Town 1 were on a rota system as were most in the other towns; only 50 to 60 per cent. felt they had adequate free time. About a third of all doctors operated an appointments system or special clinic more often, but whereas very few in Town 1 had private patients, more than half those in Town 2 accepted private patients, and more than one in five did so in Town 3. Dissatisfaction with their training in therapeutics on the part of doctors was greatest 
in Town 1, but their awareness of the toxic effects likely to be due to five frequently-employed drugs or groups of drugs did not differ from that of their colleagues in other towns. Almost two-thirds of the doctors in Town 3 were satisfied with their training in therapeutics. Half the doctors in Town 2 were likely to regard themselves as isolated from the N.H.S. in general, which was more than in the other towns. Doctors in Town 3 were the best pleased with their own area as a satisfactory one in which to practise medicine: on the other hand, nearly a third of them also felt that there was quite a lot of competition for patients in their area, as did a third of those in Town 1. Only one doctor ( 2 per cent.) felt this to be the case in Town 2 . If faced with an illness in their own family, half the doctors in Towns 1 and 2 were likely to call in a fellow G.P. in the first instance; two in three of those in Town 3 were likely to do so. One in five doctors in Town 3, one in six in Town 2, but only one in 24 in Town 1 subscribed to the Lancet.

The mean list size of the doctors in Town 3 was significantly the smallest, as was the number of consultations: however, they undertook most midwifery. The patterns in Towns 1 and 2 resembled each other (Table II). Doctors in Town 3 had significantly more contacts with hospitals and believed that they made most use of such ancillary services as "Meals on Wheels", Home Helps, W.V.S. Services, Social work agencies, etc. (Table III). Town 1 doctors had the most frequent contact

TABLE II

MEAN ( S.E.) LIST SIZE, CONSULTATION, HOME VISIT, AND MIDWIFERY RATES IN THE THREE TOWNS

\begin{tabular}{c|c|c|c|c}
\hline Town & $\begin{array}{c}\text { Consulta- } \\
\text { tions/wk }\end{array}$ & Visits/wk & Deliveries/yr & List Size \\
\hline 1 & 255 & 97 & 42 & 3,038 \\
2 & 256 & 89 & 44 & 3,349 \\
3 & 201 & 96 & 56 & 2,624 \\
\hline Total & $243 \cdots 9$ & $93 \pm 3$ & $47 \pm 3$ & $3,074 \pm 117$ \\
\hline
\end{tabular}

TABLE III

MEAN NUMBER OF MONTHLY CONTACTS WITH VARIOUS SERVICES

\begin{tabular}{c|c|c|c|c}
\hline Town & Hospital & Consultant & M.O.H. & $\begin{array}{c}\text { Ancillary } \\
\text { Services }\end{array}$ \\
\cline { 2 - 4 } 2 & 66 & $5 \cdot 8$ & $1 \cdot 6$ & $7 \cdot 5$ \\
2 & 55 & $3 \cdot 4$ & $2 \cdot 7$ & $6 \cdot 8$ \\
3 & 87 & $4 \cdot 9$ & $1 \cdot 7$ & $8 \cdot 2$ \\
\hline Total & 66 & $4 \cdot 4$ & $2 \cdot 1$ & $7 \cdot 4$ \\
\hline S.E. & $\pm 5 \cdot 3$ & $\pm 0 \cdot 5$ & $\pm 0 \cdot 3$ & $\pm 0 \cdot 2$ \\
\hline
\end{tabular}

with consultants; Town 2 doctors with their M.O.H.

The patterns of morbidity perceived by the doctors in the three towns were not very different (Table IV), although doctors in Town 3 believed that they had seen more social and marital problems and more behavioural disorders in children than those in the other towns, although, surprisingly, they reported fewer cases of depressive illness. The doctors of Town 3 were also least likely to feel that their patients came with trivial complaints, that they waited until their illness was in an of advanced state, that they made excessive demands upon the doctor in some way, or that they were "bottle conscious". The proportion of prescriptions considered to be written to please the doctor or the $\frac{\mathrm{O}}{\mathrm{O}}$ patient, rather than with a pharmacological intent, was also lowest in Town 3, although the differences were small.

Opinions about the value of different sources of information are notoriously unreliable, but it was $\partial$ noteworthy that two out of three doctors in Town 3 을 (more than twice as many as in Town 1) had been on one or more postgraduate courses since qualifying, and one in four (six times as many as in Town 1) had made some use of tape recordings for self education. Doctors in Town 3 also had a highe opinion of advertisements than their colleagues and took a slightly higher average number of journalse Neither of these differences was significant. When the three towns were ranked by the four assessors on each of the sixteen agreed measures (Appendix), Town 3 was considered to possess the best-trained and most highly-qualified doctors, who were most aware of the whole person, and organized their practice most efficiently. However, the differences assessed in this way were small and insignificant. There was no difference at all with respect to the overall quality of the practice.

\section{PART II. Differences between Doctors}

The sixteen judgements about each doctor were economically combined in a form of multivariate analysis (Harman, 1960) in which no a priori assumptions are made about the relationship between the observed variables and hypothetical underlying factors. Variation is attributed to as few factors as possible (the maximum number of factors is equal to the number of variables), and their possible nature is subsequently determined by inspecting the loadings of the variables upon each factor. Scale No. 16 (overall quality of practice) was significantly $(\mathrm{P}<0 \cdot 01)$ correlated with twelve of the other scales; and the first factor loadings of the sixteen scales were scarcely different from the corresponding correlation coefficients. Factor I.1 
TABLE IV

A. ESTIMATED CASES SEEN IN PREVIOUS MONTH (Percentage of Doctors in each Town giving Estimates above the Median for all Towns)

\begin{tabular}{|c|c|c|c|c|c|c|c|}
\hline \multicolumn{2}{|l|}{ Problems } & Depression & $\begin{array}{l}\text { Behaviour } \\
\text { Disorders in } \\
\text { Children }\end{array}$ & $\begin{array}{l}\text { Coronary } \\
\text { Disease }\end{array}$ & $\underset{\text { Problems }}{\text { Marital }}$ & $\begin{array}{c}\text { Social } \\
\text { Problems }\end{array}$ & Old Age \\
\hline \multicolumn{2}{|c|}{ Median (No. of Cases) } & 3 & 2 & 10 & 5 & 20 & 12 \\
\hline \multirow{3}{*}{$\begin{array}{l}\text { Percentages } \\
\text { of Doctors } \\
\text { above } \\
\text { Median in } \\
\text { Town }\end{array}$} & 1 & $50^{*}$ & 50 & 58 & 46 & 54 & 54 \\
\hline & 2 & 55 & 48 & 45 & 50 & 39 & 50 \\
\hline & 3 & 44 & 56 & 40 & 60 & 64 & 52 \\
\hline
\end{tabular}

B. ATTITUDE TO PATIENTS (Percentage of Doctors in each Town giving Estimates above the Median for all Towns)

\begin{tabular}{|c|c|c|c|c|c|c|}
\hline \multicolumn{2}{|c|}{$\begin{array}{l}\text { Doctors' Opinion } \\
\text { of Patients }\end{array}$} & $\underset{\text { Trivial Complaints }}{\text { Making }}$ & $\begin{array}{l}\text { Waiting until Illness } \\
\text { too far Advanced }\end{array}$ & $\begin{array}{c}\text { Making } \\
\text { Excessive Demands }\end{array}$ & Medicine-Conscious & $\begin{array}{l}\text { Requiring Scripts for } \\
\text { Frank Placebos }\end{array}$ \\
\hline \multicolumn{2}{|c|}{$\begin{array}{l}\text { Median (per cent. of } \\
\text { Patients) }\end{array}$} & 20 & 2 & 2 & 75 & 10 \\
\hline \multirow{3}{*}{$\begin{array}{l}\text { Percentages } \\
\text { of Doctors } \\
\text { above } \\
\text { Median in } \\
\text { Town }\end{array}$} & 1 & $54^{*}$ & 42 & 42 & 75 & 50 \\
\hline & 2 & 59 & 64 & 61 & 59 & 52 \\
\hline & 3 & 48 & 24 & 24 & 44 & 44 \\
\hline
\end{tabular}

* Percentage of doctors in each town giving estimates above Grand Median for all three towns.

TABLE V

LOADINGS $(\times 100)$ OF FIRST THREE INTERVIEW FACTORS

\begin{tabular}{|c|c|c|c|c|c|c|c|c|c|c|c|c|c|c|c|c|c|}
\hline \multirow{2}{*}{ Factor } & \multicolumn{16}{|c|}{ Scale (see Appendix) } & \multirow{2}{*}{$\begin{array}{l}\text { Per cent. } \\
\text { Total } \\
\text { Variance }\end{array}$} \\
\hline & 1 & 2 & 3 & 4 & 5 & 6 & 7 & 8 & 9 & 10 & 11 & 12 & 13 & 14 & 15 & 16 & \\
\hline I.1 & 49 & 31 & 61 & -04 & 35 & 50 & 40 & 73 & 80 & 77 & 67 & 57 & 60 & 31 & -03 & 93 & $31 \cdot 8$ \\
\hline I.2 & 08 & -06 & 09 & 35 & -12 & 61 & 62 & 02 & -22 & -35 & -20 & -26 & -01 & 52 & 79 & 02 & $13 \cdot 1$ \\
\hline I.3 & 45 & 60 & -08 & -37 & 69 & -13 & -05 & 16 & -15 & -26 & -14 & -39 & 10 & -09 & 15 & -04 & $9 \cdot 6$ \\
\hline $\mathrm{I} .4$ to $\mathrm{I} .16$ & & & & & & & & & & & & & & & & & $45 \cdot 5$ \\
\hline
\end{tabular}

contributed nearly a third of the total variance (Table V), and it appeared reasonable to label this the "quality of practice" factor. The contributions to the total variation of the next two factors made up a further 23 per cent., and those of the remaining factors were small. Their possible meaning was not pursued. The loadings on Factor I.2 are highest for variables $6,7,14$, and 15-holistic approach, psychosocial awareness, nonconformity, and positive attitude to change. This factor may be tentatively thought of as the "progressive" and "personoriented" component. Factor I.3 was related to training and qualifications, but also to work-load distribution (the ratio between surgery consultations and home visits). Its interpretation is not simple, but the educational aspect may be easiest to grasp. It can therefore be referred to as the "educational" variable.
An individual score on each factor can also be derived for each doctor, and the distribution of high and low loadings on each factor is summarized in Table VI. There are more doctors with high loadings on each factor in Town 3, but the differences

TABLE VI

NUMBER OF DOCTORS IN EACH TOWN HAVING LOADINGS ABOVE (HIGH) AND BELOW GRAND MEDIAN (LOW) ON FIRST THREE FACTORS.

\begin{tabular}{|c|c|c|c|c|c|c|c|}
\hline \multirow{2}{*}{$\frac{\text { Factor }}{\text { Loading }}$} & & \multicolumn{2}{|c|}{ I. 1} & \multicolumn{2}{|c|}{ I. 2} & \multicolumn{2}{|c|}{$\mathbf{I} .3$} \\
\hline & & Low & High & Low & High & Low & High \\
\hline \multirow{3}{*}{ Town } & 1 & 12 & 12 & 13 & 11 & 15 & 9 \\
\hline & 2 & 25 & 19 & 23 & 21 & 24 & 20 \\
\hline & 3 & 9 & 16 & 10 & 15 & 7 & 18 \\
\hline \multicolumn{2}{|c|}{ Total } & 46 & 47 & 46 & 47 & 46 & 47 \\
\hline
\end{tabular}


are significant only in the case of I.3. These distributions are consistent with the observations reported. The answers to the interview questions given by the doctors with the five highest and the five lowest scores on each factor, regardless of town, were also compared.

The doctors with the highest positive scores on Factor I.1 were in larger partnerships, made more home visits, attended more midwifery cases, and had more outside interests. They were less inclined to think their patients made excessive demands or attended with trivial complaints; they were more aware of unwanted effects of drugs, attended more postgraduate courses, and felt less isolated and less in competition with their colleagues.

Doctors scoring positively on Factor I.2, compared with the negative scorers, had a smaller load in every way, reported fewer instances of the medical conditions specifically inquired about, felt less isolated, and were more content with their free time. They also reported fewer problems with drug toxicities, particularly with chlorpromazine, and in general were more satisfied with their training in therapeutics. Perhaps not surprisingly, they also considered that a larger proportion of their prescriptions were for frank placebos.

The doctors with positive scores on Factor I.3 were less likely to work alone or in smaller partnerships; they had a higher work-load and reported higher morbidities of all kinds; they believed they were consulted for fewer trivial complaints; they $\mathcal{D}$ had more contacts with hospitals, consultants, and M.Os.H. than their colleagues. They were more likely to consult a G.P. than a consultant for illness ? in their own family, and in general felt less isolated $\overrightarrow{\vec{F}}$ than their colleagues with high scores on this factor. They were more critical of their training in therapeutics.'

\section{Part III. Analysis of Prescribing}

The procedure for compiling a complete record ڤ of each doctor's prescriptions during the particular $\overrightarrow{0}$ month of the study has been described by Lee (1964) and the basis of the pharmacological classifi- $\vec{\omega}$ cation by Weatherall (1964). The prescriptions were divided into fourteen groups according to the mode $\stackrel{\circ}{\frac{1}{3}}$ of administration (so that ointments, eye drops, and other local applications were separated from drugs $N$ for systemic use) and the system on which the $\omega$ remedy was expected to have its main effect. The $\vec{\partial}$ mean frequencies of prescribing calculated for the 0 93 doctors studied (Table VII) were based on the $\stackrel{3}{\overrightarrow{ }}$ same information as those given by Lee (1964) and $C_{\bar{C}}$ Weatherall (1964) for 320 doctors but are here $\stackrel{一}{₹}$ shown as prescriptions per doctor instead of per $\vec{\varphi}$ 1,000 patients and so do not correspond exactly the estimates in the previous papers. The individu frequencies which give rise to the tabulated mear are widely scattered, and their distribution positively skewed, as the standard deviations for all

TABLE VII

MEAN NUMBER OF PRESCRIPTIONS ISSUED IN MONTH OF STUDY BY EACH DOCTOR INTERVIEWED

\begin{tabular}{|c|c|c|c|c|c|}
\hline & lass of Remedy & $\begin{array}{l}\text { Town } 1 \\
(n=24)\end{array}$ & $\begin{array}{l}\text { Town 2 } \\
(n=44)\end{array}$ & $\begin{array}{l}\text { Town } 3 \\
(n=25)\end{array}$ & $\begin{array}{c}\text { All Towns } \\
\text { M } \underset{\text { M.D. }}{ \pm} \text {. S.D. } \\
(n=93)\end{array}$ \\
\hline \multirow{8}{*}{ (a) Systemic } & 1. Alimentary & 102 & 110 & 62 & $95 \pm 44$ \\
\hline & 2. Cardiovascular & 61 & 51 & 28 & $47 \pm 29$ \\
\hline & 3. Central nervous system & 348 & 371 & 201 & $319 \pm 154$ \\
\hline & 4. Genito-urinary & 43 & 46 & 24 & $39 \pm 23$ \\
\hline & 5. Chemotherapeutic & 110 & 121 & 105 & $114 \pm 64$ \\
\hline & 6. Metabolic & 95 & 95 & 54 & $84 \pm 54$ \\
\hline & 7. Respiratory & 197 & 182 & 107 & $166 \pm 75$ \\
\hline & 8. Allergic & 25 & 18 & 18 & $20 \pm 14$ \\
\hline \multirow{3}{*}{ (b) Local } & 9. Ears & 9 & 9 & 6 & $8 \pm 6$ \\
\hline & 10. Eyes & 17 & 18 & 12 & $16 \pm 9$ \\
\hline & 11. Skin & 75 & 79 & 57 & $72 \pm 34$ \\
\hline \multirow{3}{*}{ (c) Sundry } & 12. Reagents & 3 & 3 & 1 & $3 \pm 2$ \\
\hline & 13. Individual Formulations & 50 & 27 & 14 & $30 \pm 31$ \\
\hline & 14. Dressings & 34 & 44 & 29 & $37 \pm 30$ \\
\hline Total & & 1,169 & 1,174 & 718 & $1,050 \pm 469$ \\
\hline
\end{tabular}


the doctors suggest. Caution is desirable in applying the usual tests of significance to distributions with such characteristics, but the mean frequency of prescribing in Town 3 was consistently lower, in most instances significantly so $(P<0.01)$ ( $F$ test of ratio of the variances between and within towns).

For individual doctors the numbers of prescriptions in different classes are all positively correlated and usually strongly so (Table VIII). The lowest correlation $(r=+0.46)$ is between medications for allergic conditions, including sera and vaccines, and drugs for respiratory disorders. Individually formulated remedies, which may include ingredients of any therapeutic class, are not strongly correlated with all other prescriptions. The many correlations about +0.8 indicate that the frequency of his prescribing is characteristic of a doctor's behaviour, and also that high frequency does not arise from zeal for a particular group of remedies. The mean of all 91 correlations is about +0.7 : this feature therefore contributes about 50 per cent. of the variance to the frequency of prescribing.

\section{TABLE VIII}

CORRELATIONS BETWEEN NUMBERS OF PRESCRIPTIONS ISSUED IN DIFFERENT CLASSES

Systemic Remedies Only

(a) Correlations above $0 \cdot 8$

CNS + Total

Skin + Total

Alimentary + Total

Metabolic + Total

Respiratory + Total

CNS + Alimentary

CNS + Skin

Genito-urinary + Total

CNS + Respiratory

Alimentary + Respiratory

(b) Correlations below 0.6

Allergic + CNS

Allergic + Genito-urinary

Respiratory + Chemotherapy

CVS + Chemotherapy

Alimentary + Allergic

Allergic + Respiratory
Allergic

Note: No correlation with the number of individual formulations rises above $0 \cdot 55$.

Principal component analysis as before (Harman, 1960) supported this unitary view of frequency. The first component (P.1) accounted for 64 per cent. of the total variance, the second (P.2) for only another 8 per cent. P. 2 was associated particularly with the prescriptions of individually-formulated remedies. No other component accounted for as much as 6 per cent. of the variance, nor did any have meaning or statistical significance.

The analysis of prescriptions was related to the analysis of practices and practitioners' attitudes by correlating the most important individual loadings on the factors obtained in both principal component analyses (I.1, I.2, I.3, P.1, and P.2). The individual loadings on these factors were treated as the variables in a final correlation analysis (Table IX). Two of the six coefficients (I.3/P.1 at $P<0.01$ and I.3/P.2 at $P<0.05)$ attained statistical significance. That between I. 2 and P.1 was close to the conventional level. On a simple view, therefore, doctors with the most satisfactory medical education were least likely to write the largest number of prescriptions. As I.3 was itself negatively associated with work-load, however, the correlation may in part have represented an effect of list size. Doctors judged to be progressive and high in awareness of the whole person (I.2) also wrote fewer scripts than their colleagues. To a small but significant extent, the best-trained doctors also avoided individual formulations. Altogether, the measures of "personality" derived from the multivariate analysis of the interviews probably contribute little more than 15 per cent. of the total variation in prescribing, and some of this no doubt overlaps other measures discussed in previous papers.

TABLE IX

CORRELATIONS OF INDIVIDUAL LOADINGS FOR INTERVIEW AND PRESCRIBING

\begin{tabular}{c|cc}
\hline & P.1 & P.2 \\
\hline$I .1$ & 0.10 & -0.07 \\
$I .2$ & -0.20 & 0.02 \\
$I .3$ & $0-.32^{*}$ & $-0.21 \dagger$ \\
\hline \multicolumn{2}{c}{$* 0.01 . \quad+P<0.05}$.
\end{tabular}

However, although more detailed connexions can in principle be sought in the case of specific diseases, few diseases are in fact uniquely related to a particular group of drugs, in the sense that only those drugs are used for the disease in question and for no other. The relationship between depression and anti-depressive drugs may appear to be an exception, but at the time of this study the use of specific anti-depressive drugs (monoamine oxidase inhibitors and imipramine) was relatively novel, not universal, and certainly not unique: amphetamine and related drugs were still commonly used, but no doubt on many occasions for such other purposes as the suppression of appetite. Nevertheless, an attempt has been made to relate these materials, derived from the two parts of the present study. The ratio of amphetamine-like to anti-depressive substances prescribed by each doctor (Figure, abscissa) was compared with the mean number of all such prescriptions per patient with depressive illness, based 


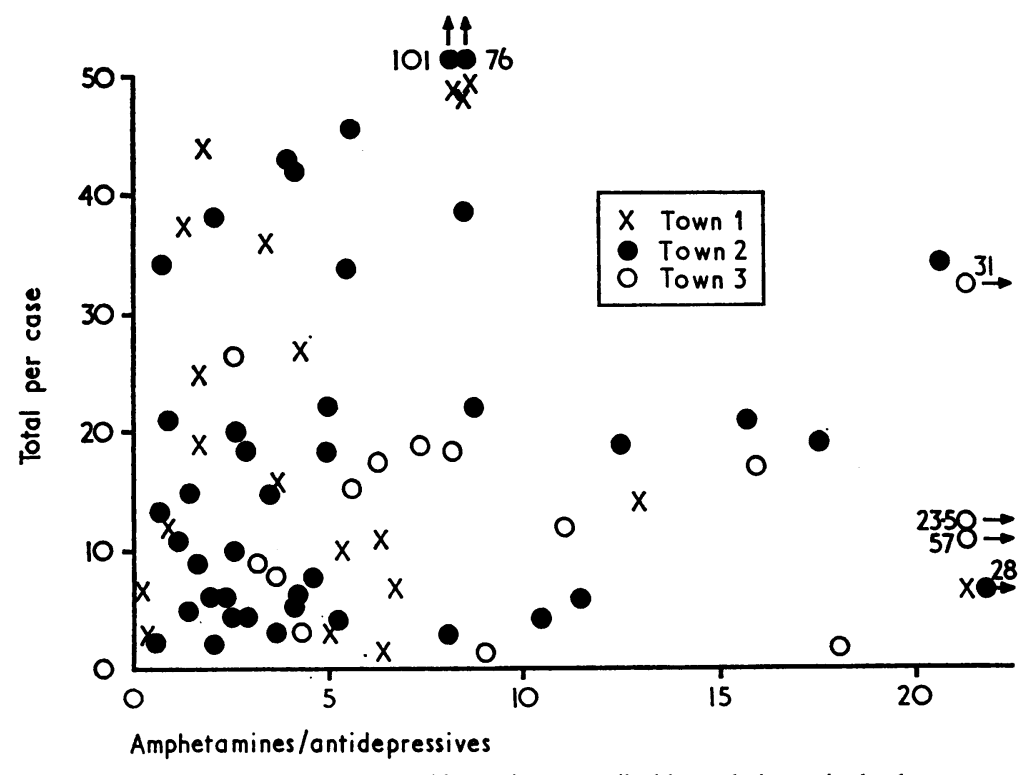

on the number in this category that the doctor believed he had seen in the previous month (ordinate: cf. Table IV).

The doctors of Towns 1 and 2 prescribed antidepressive drugs more than did those of Town 3; if those in Town 3 prescribed such drugs at all they were more likely to prescribe amphetamines. The doctors of Town 3 thus prescribed relatively little, but the drugs they prescribed were old rather than new. With the doctors of Town 1 it was the reverse, and those of Town 2 in general prescribed most, using old drugs. Since the ratio of new to old drugs may have reflected nothing so much as the success of the pharmaceutical companies in selling them at this time, the characteristics of the doctors who differed from each other in respect of the number and kind of anti-depressive drugs they prescribed have not been further explored: the principal reasons for the differences in prescribing habits between towns are still elusive.

\section{SUMmaRY}

Reasons for differences in the rates of prescribing by general practitioners were sought in an examination of their practices, characteristics, and attitudes to medical problems. 93 randomly selected doctors with large lists in three industrial towns were studied. Their replies to items in a semi-structured personal interview by a fellow general practitioner were compared. Small but clear differences appeared between the patterns typical of the three towns. The protocols were condensed by four judges into sixteen qualitative scales and the patterns were not lost in so doing. Multivariate analysis of these scales yielded three factors of apparent significance, tentatively labelled "quality of practice", "wholes person orientation", and "education". Similaro statistical analysis of the prescriptions written by. these doctors in a single month yielded two other factors, one related to overall frequency of prescribing, the other to the prescribing of individuallyformulated remedies. Three of the six correlations between the individual doctors' scores on these two unrelated sets of observations approached or exceeded conventional levels of statistical significance, but it was estimated that not more than 15 per cent. of the variation in individual patterns of prescribing could have been accounted for by the personal factors studied with the help of the interview. In general, higher educational qualifications and an orientation towards the whole person were associated with lower prescribing of drugs of all kinds.

Very many people have helped on this work with their labour, criticism, or both. We should like particularly to thank Professors J. N. Morris and J. A. H. Lee, Drs A. Heady, D. Pattison, and P. Draper, and Mr M. Power, all now or formerly of the M.R.C. Social Medicine Research Unit, London Hospital, E.1; and Mr M. J. R. Healy, at that time of the A.R.C. Experimental Station, Rothampstead. Other acknowledgements made in the papers of this series already cited should be warmly endorsed. Miss Jean Heard gave particular assistance with computing. 


\section{REFERENCES}

Benjamin, B., and Ash, R. (1964). J. roy. statist. Soc., A127, 165 (Prescribing information and management of the N.H.S. pharmaceutical service).

Harman, H. H. (1960). "Modern Factor Analysis." University of Chicago Press, Chicago.

Lee, J. A. H. (1964). Proc. roy. Soc. Med., 57, 1041 (Prescribing and other aspects of general practice in the towns).

- Draper, P. A., and Weatherall, M. (1965). Milbank mem. Fund. Quart., 43, 285 (Primary medical care. Prescribing in three English towns).

Martin, J. P. (1957). "Social Aspects of Prescribing." Heinemann, London.

Ministry of Health (1964). "Report. The Health and Welfare Services, 1963." H.M.S.O., London.

Weatherall, M. (1964). Proc. roy. Soc. Med., 57, 1043 (Pharmaceutical aspects of prescribing and classification of drugs).
APPENDIX

ATTRIBUTES OF DOCTORS EXTRACTED FROM INTERVIEWS

SCALE

1. Adequacy of training

2. Impressiveness of qualifications.

3. Organization of practice.

4. Work-load.

. Distribution of work-load.

. Psychosocial awareness.

Holistic approach.

Quality of sources of information

9. Integration into N.H.S.

Satisfaction.

Consistency of answers.

Security.

Existence of special interests.

Attitude to change.

Non-conformity.

Overall quality of practice. 